medRxiv preprint doi: https://doi.org/10.1101/2020.07.07.20145979; this version posted July 8, 2020. The copyright holder for this preprint (which was not certified by peer review) is the author/funder, who has granted medRxiv a license to display the preprint in perpetuity. It is made available under a CC-BY-NC 4.0 International license .

\title{
Effectiveness of Ivermectin as add-on Therapy in COVID-19 Management
}

\author{
(Pilot Trial)
}

\author{
Faiq I Gorial ${ }^{1 *}$, Sabeeh Mashhadani ${ }^{2}$, Hend M Sayaly ${ }^{3}$, Basim Dhawi Dakhil ${ }^{4}$, Marwan \\ M.AlMashhadani ${ }^{5}$, Adnan M Aljabory ${ }^{6}$, Hassan M Abbas ${ }^{7}$, Mohammed Ghanim 8, Jawad I \\ Rasheed ${ }^{9}$ \\ 1,2,6 Department of Medicine, College of Medicine, University of Baghdad, Baghdad, Iraq \\ 3,4,5,7,8,9 Medical City Teaching Hospital, Baghdad, Iraq \\ - Corresponding author email: faiqig@gmail.com
}

\begin{abstract}
Background: To date no effective therapy has been demonstrated for COVID-19. In vitro, studies indicated that ivermectin (IVM) has antiviral effect.

Objectives: To assess the effectiveness of ivermectin (IVM) as add-on therapy to hydroxychloroquine (HCQ) and azithromycin (AZT) in treatment of COVID-19.

Methods: This Pilot clinical trial conducted on hospitalized adult patients with mild to moderate COVID-19 diagnosed according to WHO interim guidance. Sixteen Patients received a single dose of IVM $200 \mathrm{Mcg} / \mathrm{kg}$ on admission day as add on therapy to hydroxychloroquine ( HCQ)and Azithromycin (AZT) and were compared with 71 controls received HCQ and AZT matched in age, gender, clinical features, and comorbidities.

The primary outcome was percentage of cured patients, defined as symptoms free to be discharged from the hospital and 2 consecutive negative PCR test from nasopharyngeal swabs at least 24 hours apart. The secondary outcomes were time to cure in both groups and evaluated by measuring time from admission of the patient to the hospital till discharge.

Results: Of 87 patients included in the study,t he mean age \pm SD (range) of patients in the IVM group was similar to controls $[44.87 \pm 10.64$ (28-60) vs $45.23 \pm 18.47$ (8-80) years, $\mathrm{p}=0.78]$ Majority of patients in both groups were male but statistically not significant [11(69\%) versus 52 (73\%), with male: female ratio 2.21 versus $2.7-, \mathrm{p}=0.72$ )

All the patients of IVM group were cured compared with the controls [ 16 (100\%) vs 69 (97.2 $\%)$. Two patients died in the controls. The mean time to stay in the hospital was significantly lower in IVM group compared with the controls ( $7.62 \pm 2.75$ versus $13.22 \pm 5.90$ days, $\mathrm{p}=0.00005$, effect size $=0.82$ ). No adverse events were observed

Conclusions : Add-on use of IVM to HCQ and AZT had better effectiveness, shorter hospital stay, and relatively safe compared with controls. however, a larger prospective study with longer follow up may be needed to validate these results.
\end{abstract}

Keywords: Ivermectin, hydroxychloroquine, azithromycin, COVID-19,

\section{Introduction}

A novel coronavirus, severe acute respiratory syndrome coronavirus 2 (SARS-CoV-2), was first identified in December 2019 as the cause of a respiratory illness designated coronavirus disease 2019, or Covid-19 with significant public health impact (1). Several therapeutic agents have 
medRxiv preprint doi: https://doi.org/10.1101/2020.07.07.20145979; this version posted July 8, 2020. The copyright holder for this preprint (which was not certified by peer review) is the author/funder, who has granted medRxiv a license to display the preprint in perpetuity. It is made available under a CC-BY-NC 4.0 International license.

been evaluated for the treatment of Covid-19, however, none have yet been shown to be effective $(2,3)$

Recently some reports on HCQ [4-6], Azithromycin [7] and Ivermectin [8] have shown therapeutic effects against novel coronavirus infection. Ivermectin is an antiparasitic drug with a broad spectrum antiviral effect Recently, in vitro study showed reduction of viral RNA in VerohSLAM cells 2 hours postinfection with SARS-CoV-2 clinical isolate Australia/VIC01/2020 (8). The authors hypothesized that the effect was likely due to the inhibition of IMP $\alpha / \beta 1$ - mediated nuclear import of viral proteins.

Because of the broad spectral antiviral activities of IVM and it is safety profile, It may offer a therapeutic potential to COVID-19. This study was designed to assess effectiveness and safety of add-on use of IVM to HCQ and AZT in COVID 19 patients.

\section{Patients and Methods}

\section{Study design}

This pilot interventional single center study with a synthetic controlled arm (SCA) was conducted at Al-Shifa'a Hospital Center from first of April to the end of May 2020. Synthetic controlled arm was used due to difficulty of using placebo for our patients and the strong preference for the investigational product in this pandemic Covid-19 disease to improve drug development and reduce patients burden. SCA is an external control constructed from patient-level data from previous patients records to match the baseline characteristics of the patients in an investigational group and augment a single-arm trial to estimate treatment effects. The SCA in this trial included previous patients who were treated by HCQ and AZT according to the Iraqi Ministry of Health protocols for treatment of covid-19.

Ethical approval of the study was taken in accordance with the Declaration of Helsinki and its amendments and the Guidelines for Good Clinical Practices issued by the Committee of Propriety Medicinal Product of the European Union from Iraqi ministry of health and the study was registered with No. 497 at April 2020. Also, this study was registered in ClinicalTrials.gov website under identifier number: NCT04343092. Informed consent was obtained from the participants to admit the study.

\section{Participants}

\section{Inclusion criteria}

Inclusion criteria were the following: 1) men and women with age at least 18 years 2) mild to moderate COVID-19 diagnosed by positive polymerase chain reaction (PCR) testing < $=3$ days from enrollment 3)Patient acceptance and willingness to comply with planned study procedures and to complete the follow up. 4) hospital admission 5) no participation in other clinical trials, such as antiviral trials, during the study period. 6) Able to provide informed consent

Mild and moderate COVID-19 were defined according to World Health Organization (WHO) interim guidance (16). Mild COVID-19 was defined as symptomatic patients meeting the case 
definition for COVID-19 without evidence of viral pneumonia or hypoxia. The symptoms included: fever, cough, fatigue, anorexia, shortness of breath, myalgias. Other non specific symptoms such as soar throat, nasal congestion, headache, diarrhea nausea, vomiting, loss of smell, loss of taste, Older people and immunosuppressed patients in particular may present with atypical symptoms such as fatigue, reduced alertness, reduced mobility, diarrhea, loss of appetite, delirium, and absence of fever. Moderate COVID-19: included adolescent or adult with clinical signs of pneumonia (fever, cough, dyspnea, fast breathing) but no signs of severe pneumonia, including $\mathrm{SpO} 2 \geq 90 \%$ on room air.

\section{Exclusion criteria}

Exclusion criteria were the following: 1) severe COVID-19 defined as respiratory distress ( $\geq 30$ breaths/min; in resting state, oxygen saturation of $93 \%$ or less on room air; or arterial partial pressure of oxygen $(\mathrm{PaO} 2)$ /fraction of inspired oxygen (FIO2) of 300 or less. 2) Life threatening COVID-19 was defined as respiratory failure requiring mechanical ventilation; shock; or other organ failure (apart from lung) requiring intensive care unit (ICU) monitoring. 3) hypersensitivity or severe adverse events to IVM, 4) Alanine Aminotransferase (ALT) or aspartate aminotransferase (AST) $>5 \mathrm{X}$ upper limit of normal (ULN) 4) pregnancy 5) breast feeding.

6) history of severe asthma.

\section{Intervention}

Patients received IVM 200 Mcg single dose at the admission day as add on therapy to Iraqi Ministry of Health protocol for treatment of mild to moderate COVID-19 [ HCQ 400mg BID for the first day then 200mg BID for 5 days plus AZT 500mg single dose in the first day then $250 \mathrm{mg}$ for 5 days]. We evaluated these patients for cure by clinical assessment and PCR swab testing. Nasopharyngeal or oropharyngeal swabs specimens were collected on days $1,3,5,7,9,11,13$, $15,17,19,21$, and 23 for viral RNA detection and quantification till two successive days of negative PCR swab testing at least 24hrours apart. Virological testing was done at Alshifa'a Hospital Laboratory Center using ABI 7500Dx Real-Time PCR System instruments (Applied Biosystems), USA.

\section{Outcomes}

The primary outcome was percentage of the cured patients within 23 days. Cure of the patients was defined by assessing proportion of patients who were symptoms free to be discharged from the hospital and included body temperature returned to normal for longer than 3 days, respiratory symptoms significantly improved, and 2 consecutive negative PCR test results from nasopharyngeal swabs at least 24 hours apart. The secondary outcomes were time to cure in both groups. Time to cure is evaluated by measuring time from admission of the patient to the hospital till discharge after being free of symptoms and negative PCR swab. Once nasopharyngeal and oropharyngeal swab viral PCR testing yielded negative results 2 times consecutively, no further testing was performed. Also safety outcomes included treatment-emergent adverse events, serious adverse events, and premature discontinuations of study were recorded if present. 
medRxiv preprint doi: https://doi.org/10.1101/2020.07.07.20145979; this version posted July 8, 2020. The copyright holder for this preprint (which was not certified by peer review) is the author/funder, who has granted medRxiv a license to display the preprint in perpetuity. It is made available under a CC-BY-NC 4.0 International license .

\section{Sampling method and sample size calculation}

A convenient consecutive sample of patients were enrolled in the study. The sample size calculated for this pilot trial was 30 patients : 15 in the active arm ( IVM group) and 15 in the controls (SCA) according to pilot study sample size rule of thumb to get medium effect size of $0.3 \leq \delta / \sigma<0.7$ with a statistical power of $90 \%$. (9)

\section{Statistical analysis}

Statistical analysis was done using R packages software for IOS. The normality of continuous variables was analyzed using Shapiro Wilk test. Continuous variables were expressed as mean \pm standard deviation (SD) if were normally distributed and median (interquartile range) if not normally distributed. Categorical variables were presented as number and percentages. Difference between normally distributed continuous variables was measured using Student's t-test and MannWhitney $U$ test if not normally distributed. Effect size for non normally distributed variables was measured using Vargha and Delany A test. Kaplan Meier survival curve analysis with and log rank testing was used. The standardized mean difference effect size is small if value 0.2-0.5; medium if value $0.5-0.8$, and large effect size if value $0.8-1.4 \mathrm{P}$ value less than 0.05 was considered statistically significant.

\section{Results}

\section{Population characteristics \\ Participant flow}

A total of 20 patients were screened for IVM add on group. Of those 4 patients were excluded: 2 of them due to severe COVID-19 and 2 had incomplete data and diagnosis. For comparison with the SCA, a total of 84 patients were screened for eligibility, of them 13 patients were excluded due to having severe COVID-19. The eligible patients in the controls were 71 patients. Two of them died during follow up and 69 completed their standard protocol of therapy according to the Iraqi ministry of health protocol of treatment of COVID-19 as shown in figure 1.

\section{Baseline characteristics}

Table 1 shows that mean age \pm SD of patients in the IVM group was $44.87 \pm 10.64$ years with a range of (28-60) years and for the controls was $45.23 \pm 18.47$ years with a range of (8-80) years. Majority of patients of IVM and controls were male [11(69\%) versus $52(73 \%)$, with male: female ratio 2.21 versus 2.7-1 respectively. Most cases of COVID-19 were mild in both groups [9(65\%) in IVM versus 40(56\%) In non IVM]. The most common clinical features in IVM group were cough 13(81\%), next fever 11(685), then shortness of breath 9(56\%). Similarly, in non IVM group, the most common clinical features were: cough $55(77 \%)$, next fever $53(74 \%)$, then shortness of breath $44(61 \%)$. Four patients in IVM group had underlying diseases: of them three had diabetes mellitus and hypertension and 1 had asthma, while in the non IVM, 29 (45\%) had underlying diseases, of them 15 had diabetes mellitus, 14 had hypertension, and seven had asthma. There was no statistical significant difference between IVM group and the controls indicating no signiant sociodemographic and clinical confounders affected the study $(p>0.05)$ 
medRxiv preprint doi: https://doi.org/10.1101/2020.07.07.20145979; this version posted July 8, 2020. The copyright holder for this preprint (which was not certified by peer review) is the author/funder, who has granted medRxiv a license to display the preprint in perpetuity. It is made available under a CC-BY-NC 4.0 International license .

\section{Outcomes and estimation}

In Table 2, All the patients $16(100 \%)$ of IVM group were cured compared to $69(97.2 \%)$ in the non IVM group. There were two patients died in the non IVM group.

The mean time to stay in the hospital was lower in IVM group compared with the controls and was statistically significant and clinically relevant $(7.62 \pm 2.75$ versus $13.22 \pm 5.90$ days, $\mathrm{p}=0.00005$ ) with large effect size $=0.82$ ) as in figure 2 .

The percentage of positive PCR patients with IVM group had significantly shorter time to become negative PCR compared to the controls. The median days of positive PCR in the IVM group was significantly lower than that of controls [7 (95\% CI 6-11) vs 12 (95\% CI 10-15), log rank test $\mathrm{p}<0.001$ respectively] as in figure 3 .

No side effects have been found in the IVM group.

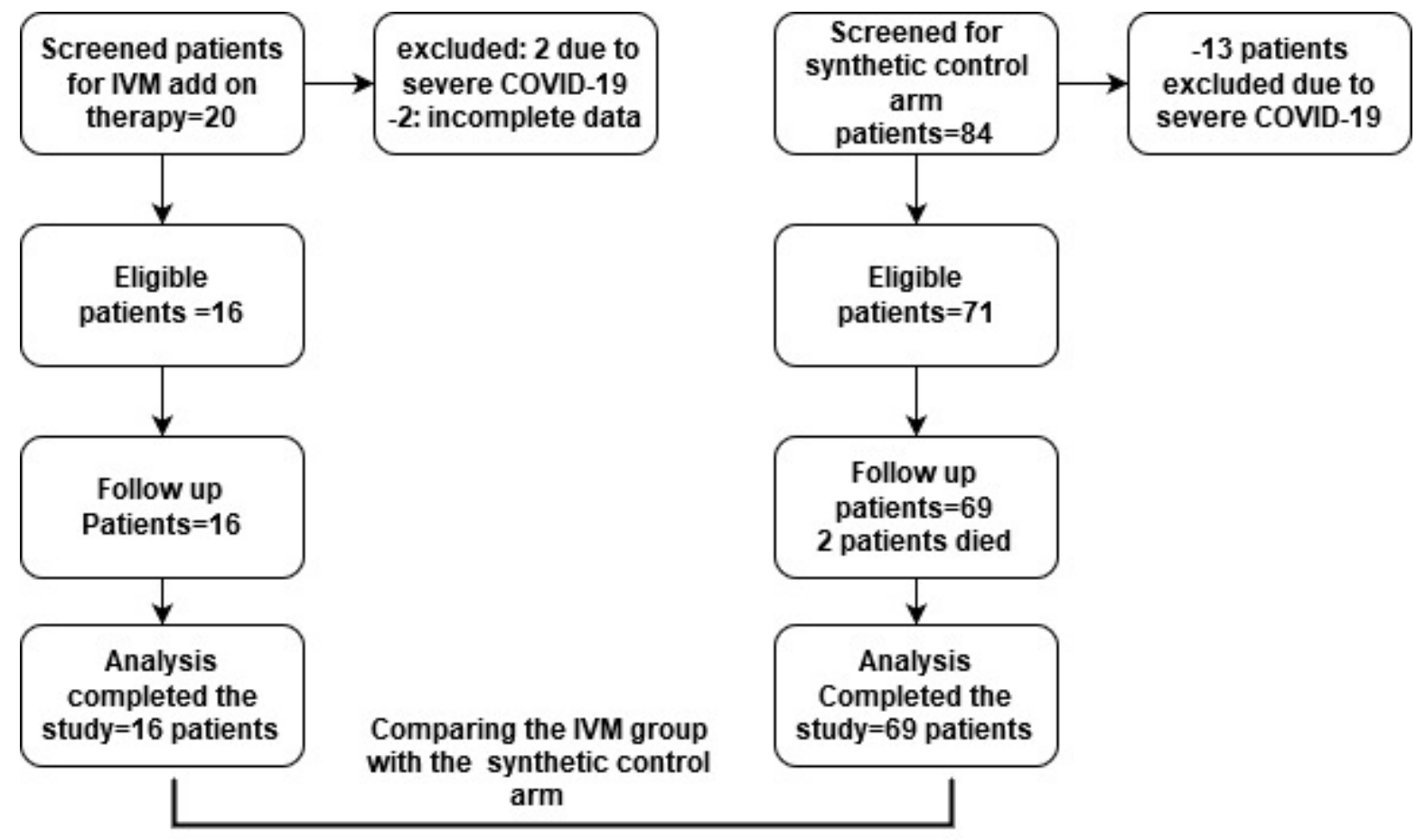

Figure 1: Flow chart of the study group. 
Table1: Baseline characteristics of IVM and Non IVM group

\begin{tabular}{|c|c|c|c|c|}
\hline Variables & Total $=87$ & IVM Group = 16 & Controls $=71$ & P value \\
\hline $\begin{array}{l}\text { Age in years, Mean } \pm \\
\text { SD (range) }\end{array}$ & $\begin{array}{l}45.17 \pm 17.25(8- \\
80)\end{array}$ & $\begin{array}{l}44.87 \pm 10.64(28- \\
60)\end{array}$ & $45.23 \pm 18.47(8-80)$ & 0.78 \\
\hline $\begin{array}{l}\text { Gender } \\
\text { Male n }((\%) \\
\text { Female n }(\%) \\
\text { Ratio male: female }\end{array}$ & $\begin{array}{l}63(72) \\
24(28)\end{array}$ & $\begin{array}{l}11(69) \\
5(31) \\
2.21\end{array}$ & $\begin{array}{l}52(73) \\
19(27) \\
2.7-1\end{array}$ & 0.72 \\
\hline $\begin{array}{l}\text { Severity } \\
\text { Mild n (\%) } \\
\text { Moderate } \mathrm{n}(\%) \\
\text { Ratio }\end{array}$ & $\begin{array}{l}49(56) \\
38(44)\end{array}$ & $\begin{array}{l}9(56) \\
7(44) \\
1.2=1\end{array}$ & $\begin{array}{l}40(56) \\
31(44) \\
1.2: 1\end{array}$ & 1.00 \\
\hline $\begin{array}{l}\text { Clinical Features } \mathrm{n}(\%) \\
\text { Cough } \\
\text { Fever } \\
\text { Shortness of breath } \\
\text { Myalgia } \\
\text { Sor throat }\end{array}$ & $\begin{array}{l}68(78) \\
64(73) \\
53(61) \\
61(70) \\
21(24)\end{array}$ & $\begin{array}{l}13(81) \\
11(68) \\
9(56) \\
8(50) \\
4(25)\end{array}$ & $\begin{array}{l}55(77) \\
53(74) \\
44(61) \\
53(74) \\
17(23)\end{array}$ & $\begin{array}{l}0.74 \\
0.63 \\
0.67 \\
0.10 \\
0.82\end{array}$ \\
\hline Underlying diseases & $\begin{array}{l}33(38) \\
\text { Diabetes } \\
\text { melitus: } 18 \\
\text { Hypertension17 } \\
\text { Asthma: } 8\end{array}$ & $\begin{array}{l}4(25) \\
\text { Diabetes melitus:3 } \\
\text { Hypertension3 } \\
\text { Asthma: } 1\end{array}$ & $\begin{array}{l}29(40) \\
\text { Diabetes mellitus:15 } \\
\text { Hypertension:14 } \\
\text { Asthma:7 }\end{array}$ & $\begin{array}{l}0.83 \\
0.79 \\
0.65\end{array}$ \\
\hline
\end{tabular}

IVM, Ivermectin; SD, standard deviation; n, number; \%, percentage

Table 2: Percentage of cure rate IVM group and Non IVM group Cure rate

\begin{tabular}{|l|l|l|}
\hline Outcome & IVM & Controls \\
\hline Cure n (\%) & $16(100)$ & $69(97.2)$ \\
Mortality n (\%) & zero\% & $2(2.8 \%)$ \\
\hline
\end{tabular}

IVM, ivermectin; $\mathrm{N}$, number; \%, percentage 


\section{$\mathrm{p}=0.00005$ \\ Effect size $=0.82$}

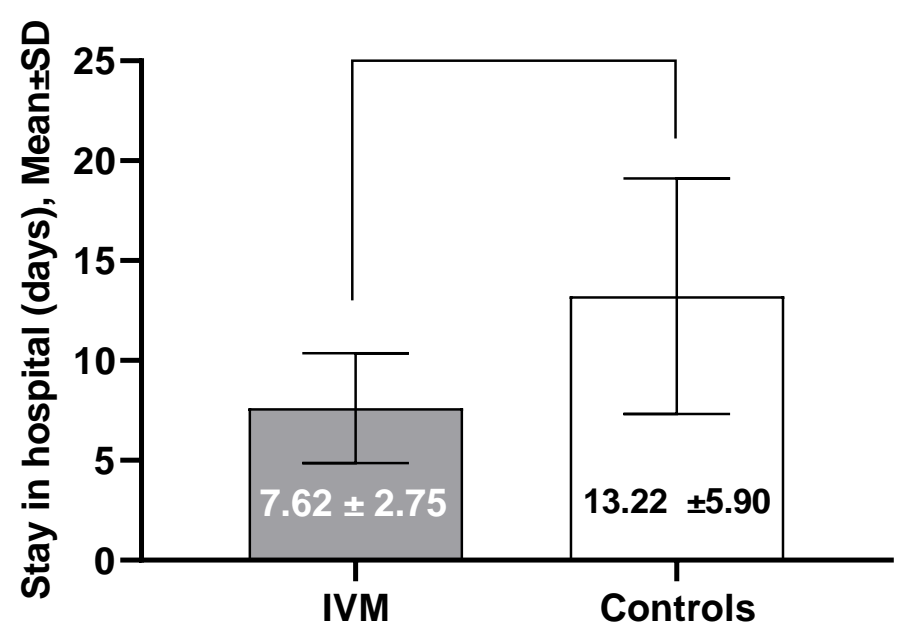

$\square$ IVM $\square$ Controls

Figure 2: Mean stay days in hospital in IVM group compared with controls 


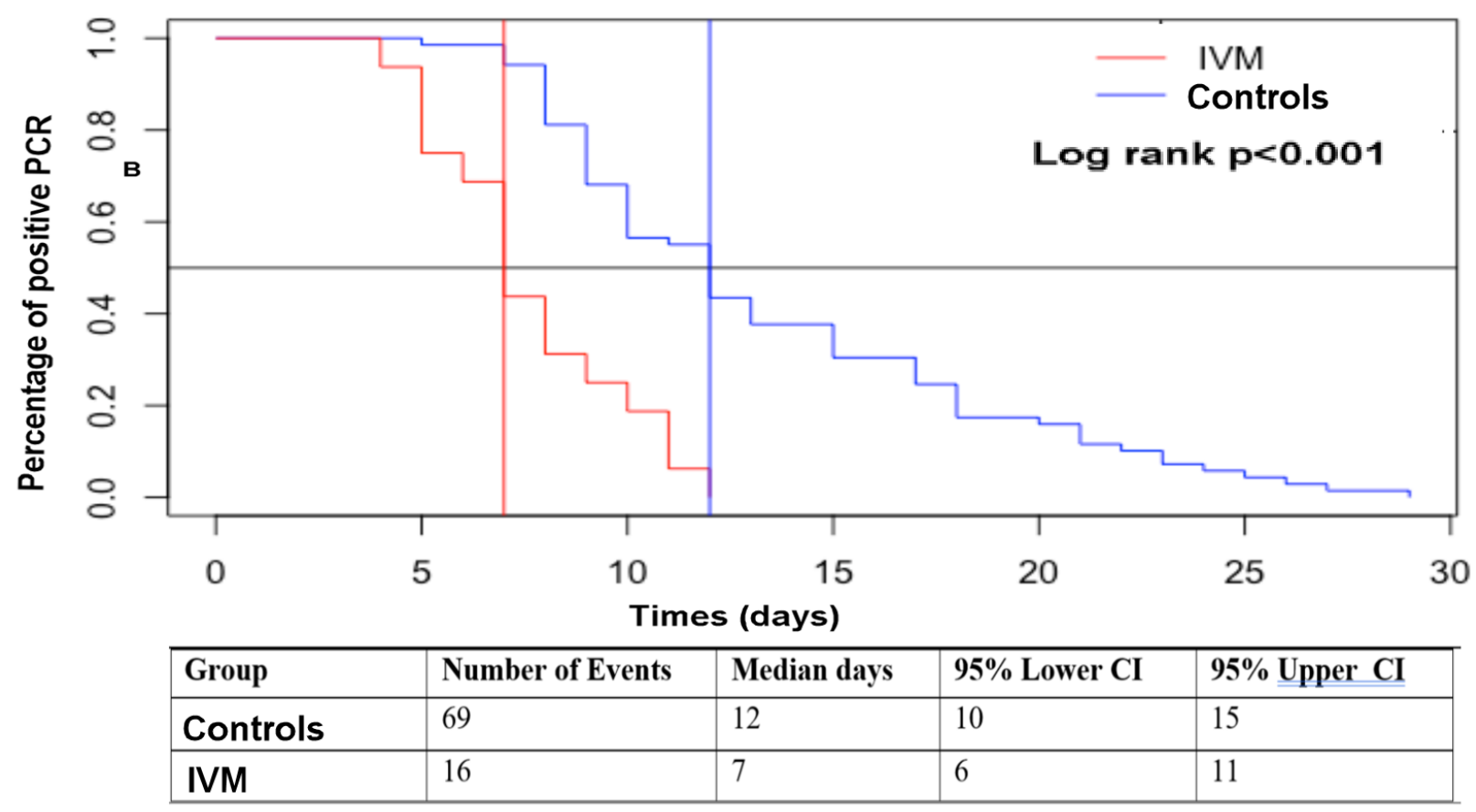

Figure 3: Kaplan Meier survival analysis curve for time to percentage of positive PCR in IVM group $(n=16)$ versus controls $(n=69)$ ( $p<0.001$, Log rank test). PCR, polymerase chain reaction; IVM, ivermectin; CI, confidence interval. The vertical red line represents the median days of IVM; The vertical blue line, represent the median days for controls.

\section{Discussion}

To date, no effective therapy has been shown for patients with COVID-19. This preliminary pilot study demonstrated for the first time that add-on use of IVM to HCQ and AZT had obvious higher cure rate, shorter hospital stay days compared with controls. In addition, there was no obvious reported adverse events.

Although data from several ongoing randomized controlled trials (RCT) for IVM will soon provide more informative evidence regarding safety and effectiveness IVM for COVID-19. The outcomes observed in this study with synthetic controls are the best available data regarding IVM use for COVID-19. In addition, during a pandemic with a potential death outcome, RCT become difficult to conduct and may be unethical. Randomization to placebo could carry a risk of serious consequences and even Food and Drug Administration (FDA) is encouraging the use of synthetic control for more innovative approaches (10).

According to the results of this study, all the patients $16(100 \%)$ in the IVM group were cured compared to $69(97.2 \%)$ in the controls. No similar study to compare with.

A Pilot observational study conducted by Gautret et al to assess the clinical and microbiological effect of a combination of HCQ and AZT in 80 COVID-19 patients with at least 
medRxiv preprint doi: https://doi.org/10.1101/2020.07.07.20145979; this version posted July 8, 2020. The copyright holder for this preprint (which was not certified by peer review) is the author/funder, who has granted medRxiv a license to display the preprint in perpetuity. It is made available under a CC-BY-NC 4.0 International license .

a six-day follow up reported that all patients recovered except three patients, one of them died and the other two admitted to the intensive care unit (11).

Another open label non randomized trial evaluated six patients taking HCQ and AZT compared with 14 patients on HCQ and 16 untreated patients from another center and cases refusing the protocol were included as negative controls reported $100 \%$ cure rate for those on combined HCQ and AZT , 57.1\% on HCQ only, and 12.5\% (p<0.001) (12)

Recently, in a large international, multicenter, observational propensity-score matched case-controlled study in 1,408 patients (704 received IVM in a dose of $150 \mathrm{mcg} / \mathrm{kg}$ and 704 that did not) showed that fewer patients of those requiring mechanical ventilation died in the IVM group (7.3\% versus $21.3 \%)$ and overall death rates were lower with IVM $(1.4 \%$ versus $8.5 \%$ with a corresponding HR 0.20 , CI 95\% 0.11-0.37, p<0.0001). They concluded an association of IVM use with lower in-hospital mortality and suggested a potential survival benefit of IVM in COVID 19 (13)

In contrast, Molina et al reported in a letter to editor that no evidence of rapid antiviral clearance or clinical benefit with the combination of HCQ and AZT in patients with severe COVID-19 infection despite a reported antiviral activity of HCQ against COVID-19 in vitro and suggested ongoing randomized clinical trials with HCQ to provide a definitive answer re garding the alleged effectiveness and its safety (14). The variation in the results in those studies may be related to their study design, included severe patients, small sample sizes, inaccurate sampling method, and short follow up with repeated qualitative PCR assay.

In a randomized, controlled trial of lopinavir-ritonavir in adults hospitalized patients with severe COVID-19 reported no significant benefit was observed with lopinavir-ritonavir treatment beyond the standard care. However, in the modified intention to-treat analysis, which excluded three patients with early death, the between-group difference in the median time to clinical improvement (median,15 days vs. 16 days) was significant, albeit modest. The overall cure rate was $77.9 \%$ in that trial. The explanation of high mortality rate possibly was related to the severely ill population enrolled in that study (15)

Moreover, in another recent trial, a preliminary report of compassionate use of remdesivir for small cohort of patients with severe COVID-19 showed an observed clinical improvement in 36 of 53 patients $(68 \%)$ and overall mortality was $13 \%$ over a median follow-up of 18 days. The relatively high mortality rate and less cure in their results may be related to the sever type of COVID-19 in their patients. (16).

Another noteworthy observation in this study was the time to stay in the hospital. The results revealed that the mean time to stay in the hospital in IVM group was $7.62 \pm 2.75$ days compared with $13.22 \pm 5.90$ days for the controls which was statistically significant $(p=0.00005)$ and clinically relevant with large effect size (Effect size $=0.82$ ). This mean shorter time to recovery and early time to discharge patient to home in those taking IVM which will help to provide more beds for another patients who need it and this is practically important in this pandemic disease. Up to our knowledge there is no other study to compare with it.

The time of rapid and full viral clearance was controversial in literatures regarding combination of HCQ and AZT. One study reported that a 100\% viral clearance in nasopharyngeal swabs in 6 patients after 5 and 6 days of the combination of HCQ and AZT (17). Another study observed that 10 patients (not done on patient who died) out of 11 patients were still positive at day 6 after initiation of treatment on repeated nasopharyngeal swab using a qualitative PCR assay (nucleic 
medRxiv preprint doi: https://doi.org/10.1101/2020.07.07.20145979; this version posted July 8, 2020. The copyright holder for this preprint (which was not certified by peer review) is the author/funder, who has granted medRxiv a license to display the preprint in perpetuity. It is made available under a CC-BY-NC 4.0 International license .

acid extraction using Nuclisens Easy Mag®, Biomerieux and amplification with RealStar SARS CoV-2®, Altona) (13).

In addition, a new study from China in individuals with COVID -19 found no difference in duration of hospitalization at 7 days with or without HCQ (18). The difference in the study design and short follow up with repeated PCR may related to the variation in the day of cure in those studies.

On comparing the mean cure days of patients in our study to the mean recovery of other medications, we found two recent studies. The first study reported the median duration of recovery with $95 \% \mathrm{CI}$ of patients receiving remdesivir compared with $\mathrm{PBO}$ was of variable ranges from 11 (9-12) days in remdesivir versus 15 (13-19) days in PBO to unestimated days in remdesivir versus 28 days in PBO (16). This variation can be explained according to the severity score of the disease on the ordinal scale of intention to treat analysis they used in their study, those patients with score four or less had less duration of cure compared to those with score seven which was an expected finding. The second study compared lopinavir/ritonavir to the standard care and showed that the median time to clinical improvement in days (interquartile range) was 16.0 (13.0 to 17.0) days in lopinavir/ritonavir group versus 16.0 (15.0 to 18.0) in the standard care group which was not significant (15).

In the current short-term study, no new safety signals were detected apart from patients' manifestations on hospital admission. There were no obvious immediate or late adverse events that occurred during treatment, and no serious adverse events that necessitate discontinuation of treatment However it is challenging to attribute any new abnormal complications in the patients whether due to IVM use or the disease itself.

The age, gender, severity of the disease, and the comorbid diseases in the IVM group were not statistically significantly different from the controls. This indicate that these variables were not significant confounders that affect our results and the findings we got were mostly due to the effect of IVM rather than those confounders.

The mechanism of better response in IVM group compared with the controls in this study may be due to the possible synergistic action of these three drugs (IVM, HCQ, and AZT). It was reported that HCQ and IVM were known to act by creating the acidic environment and inhibiting the importin (IMP $\alpha / \beta 1)$ mediated viral import. AZT was found to act similar to the HCQ as an acidotropic lipophilic weak base. All the three categories of drugs seemed to potentially act against COVID 19. infection (19).

This study had some strengths. It is the first externally controlled pilot trial; performed in a public hospital, strict exclusion and inclusion criteria, and presented for the first time assessment of the effectiveness and safety of add on use of IVM to HCQ and AZT. However, this study has some limitations, including its small sample size; single center design, short time for the study, and being nonrandomized.

In conclusion, this study showed that adding IVM to HCQ and AZT had a better cure rate and shorter time to stay in the hospital compared with controls. In addition, it was relatively safe without observable safety signals. These findings may suggest using IVM as an add on therapy to protocols used for treatment of COVID-19. However, these results are needed to be validated in a larger prospective follow up study. The results of the study must not be considered conclusive since unknown confounders cannot always be reliably accounted and we recommend further 
medRxiv preprint doi: https://doi.org/10.1101/2020.07.07.20145979; this version posted July 8, 2020. The copyright holder for this preprint (which was not certified by peer review) is the author/funder, who has granted medRxiv a license to display the preprint in perpetuity. It is made available under a CC-BY-NC 4.0 International license .

studies. A national multicenter randomized study is planned to perform in different provinces of Iraq using IVM alone since HCQ is temporary withdrawn from the COVID 19 therapy according to the WHO advice.

\section{Acknowledgements}

We thank all the participant patients in the study. Also, we thank the medical staff who helped us in data collection.

\section{References}

1. Helmy YA, Fawzy M, Elaswad A, Sobieh A, Kenney SP, Shehata AA. The COVID-19 pandemic: a comprehensive review of taxonomy, genetics, epidemiology, diagnosis, treatment, and control. J Clin Med 2020;9(4):E1225.

2. Cao B, Wang Y, Wen D, et al. A trial of lopinavir-ritonavir in adults hospitalized with severe Covid-19. N Engl J Med 2020; 382:1787-99.

3. Borba MGS, Val FFA, Sampaio VS, et al. Effect of high vs low doses of chloroquine diphosphate as adjunctive therapy for patients hospitalized with severe acute respiratory syndrome coronavirus 2 (SARS-CoV-2) infection: a randomized clinical trial. JAMA Netw Open 2020;3(4): e208857.

4. Liu J, Cao R, Xu M. et al. Hydroxychloroquine, a less toxic derivative of chloroquine, is effective in inhibiting SARS-CoV-2 infection in vitro. Cell Discov 2020; 6: 16.

5. Yao X, Ye F, Zhang M, et al. In vitro Antiviral Activity and Projection of Optimized Dosing Design of Hydroxychloroquine for the Treatment of Severe Acute Respiratory Syndrome Coronavirus 2 (SARS-CoV-2) [published online ahead of print, 2020 Mar 9]. Clin Infect Dis 2020; ciaa237. doi:10.1093/cid/ciaa237

6. Gautret, P. et al. Hydroxychloroquine and azithromycin as a treatment of COVID19: results of an open-label non-randomized clinical trial. Int J Antimicrob Agents 2020; n105949, doi:10.1016/j.ijantimicag.2020.105949.

7. Poschet JF, Perkett EA, Timmins GS, Vojo Deretic. Azithromycin and ciprofloxacin have a chloroquine-like effect on respiratory epithelial cells. bioRxiv 2020.03.29.008631; doi: https://doi.org/10.1101/2020.03.29.008631

8. Caly L, Druce JD, Catton MG, Jans DA, Wagstaff KM. The FDA-approved Drug Ivermectin inhibits the replication of SARS-CoV-2 in vitro. Antiviral Research Available online 3 April 2020, 104787

9. Canga AG, Prieto AM, Liébana MJ, Martínez NF, Vega MS, Vieitez JJ. The pharmacokinetics and interactions of ivermectin in humans - a mini-review. The AAPS journal. 2008 Mar 1;10(1):42-6.

10. Whitehead, A.L., Julious, S, Cooper, C.L., Campbell, M.J. 'Estimating the sample size for a pilot randomised trial to minimise the overall trial sample size for the external pilot and main trial for acontinuous outcome variable'.Stat Meth Med Res 2016; 25(3):1057-1073.

11. U.S Food and Drug Administration. Real World Evidence Program. 2018;(February).

12. Gautret P, Lagier JC, Parola P, et al. Clinical and microbiological effect of a combination of hydroxychloroquine and azithromycin in 80 COVID-19 patients with at least a six-day 
medRxiv preprint doi: https://doi.org/10.1101/2020.07.07.20145979; this version posted July 8, 2020. The copyright holder for this preprint (which was not certified by peer review) is the author/funder, who has granted medRxiv a license to display the preprint in perpetuity. It is made available under a CC-BY-NC 4.0 International license.

follow up: A pilot observational study. Travel Med Infect Dis. 2020;34:101663. doi:10.1016/j.tmaid.2020.101663

13. Gautret P, Lagier JC, Parola P, et al. Hydroxychloroquine and azithromycin as a treatment of COVID-19: results of an open-label non-randomized clinical trial [published online ahead of print, 2020 Mar 20]. Int J Antimicrob Agents. 2020;105949. doi:10.1016/j.ijantimicag.2020.105949

14. Patel A. Usefulness of Ivermectin in COVID-19 Illness. Available at SSRN 3580524. 2020 Apr 19.

15. Molina JM, Delaugerre C, Le Goff J, et al. No evidence of rapid antiviral clearance or clinical benefit with the combination of hydroxychloroquine and azithromycin in patients with severe COVID-19 infection. Med Mal Infect. 2020;50(4):384. doi:10.1016/j.medmal.2020.03.006

16. Cao B, Wang Y, Wen D, et al. A Trial of Lopinavir-Ritonavir in Adults Hospitalized with Severe COVID-19. N Engl J Med. 2020;382(19):1787-1799. doi:10.1056/NEJMoa2001282

17. Grein J, Ohmagari N, Shin D, et al. Compassionate Use of Remdesivir for Patients with Severe COVID-19 [published online ahead of print, 2020 Apr 10]. $N$ Engl J Med. 2020;NEJMoa2007016. doi:10.1056/NEJMoa2007016

18. Chen J, Liu D, Lui L, et al. A pilot study of hydroxychloroquine in treatment of patients with common coronavirus disease-19 COVID-19). J Zhejiang Univ Sci 2020;49(2):215219.

19. Choudhary R, Sharma AK. Potential use of hydroxychloroquine, ivermectin and azithromycin drugs in fighting COVID-19: trends, scope and relevance. New Microbes and New Infections. 2020 Apr 22:100684. 